\title{
Malignant Pleural Mesotheliomas: An Environmental Health Risk in Southeast Turkey
}

\author{
K.M. Müller M. Fischer \\ Institut für Pathologie und deutsches Mesotheliumregister, Berufsgenossenschaftliche Kliniken Bergmannsheil, \\ Universitätsklinik, Bochum, Deutschland
}

Natural asbestos deposits pose a health hazard not to be neglected in some European and non-European countries.

According to our information, about 113 asbestos deposits are known in Turkey, of which $65 \%$ contain chrysotile, $39 \%$ tremolite and $1 \%$ crocidolite. Whereas industrial exploitation is only of minor importance, domestic and agricultural use play a more important role, the farming of asbestos-containing land and the domestic use of asbestos-containing white-wash, roofing, cleaning liquids and toothpaste causing sometimes considerable exposure to asbestos dusts. In recent years, the high hazards in the respective areas of Southern Turkey have led to an intensive public information campaign organized by the medical professions and the authorities. As a result of these campaigns, Senyigit et al. [1] register a decline in the incidence of mesothelioma in a number of affected areas. Thus, the rise in frequency of mesothelioma in regions previously not known in this respect is a marked signal for investigating the danger potential and health hazards.

In their paper on the incidence of malignant pleural mesothelioma and on CT findings in 117 patients, published in this issue of Respiration, Senyigit et al. [1,2] approach this subject in a remarkable way. The results and conclusions drawn from investigations over a comparatively long period of time are convincing. Regarding

\begin{tabular}{ll}
\hline KARGER & ( ) 2000 S. Karger AG, Basel \\
0025-7931/00/0676-0608\$17.50/0 \\
$\begin{array}{l}\text { Fax +4161306 12 34 } \\
\begin{array}{l}\text { E-Mail karger@karger.ch } \\
\text { www.karger.com }\end{array}\end{array}$ & $\begin{array}{l}\text { Accessible online at: } \\
\text { www.karger.com/journals/res }\end{array}$
\end{tabular}

the purely environmental exposure, the investigated patient collective has a very homogeneous structure. The explanation for the nearly equal sex ratio (male:female 1:1.3) in its differentiation from the ratio after occupational exposure is plausible. The statements concerning a possibly higher incidence than the calculated one reflect the general problems connected with patient inherent and demographic factors. The long latency periods until the development of malignant mesothelioma put into perspective, for the time being, the assessment of preventive measures.

The varying carcinogenicity of the inhaled asbestos fiber types is mentioned as one very important factor. In the past, the views concerning tremolite especially varied considerably. Now, however, it is widely believed that the carcinogenic potency of tremolite is much higher than that of chrysotile.

The knowledge of natural asbestos fibre types is of decisive importance in cases where environmental exposure has to be differentiated from occupational exposure. We are frequently confronted with such issues of differentiation, these cases include Turkish patients developing mesothelioma after their emigration to Germany. All patients are comparatively young $(<50$ years) at the time of falling ill, compared to $>60$ years after purely occupational exposure. The share of females affected is markedly

Prof. Dr. med. K.M. Mülle

Institut für Pathologie, Berufsgenossenschaftliche Kliniken Bergmannsheil

Universitätsklinik, Bürkle-de-la-Camp-Platz 1

D-44789 Bochum (Germany)

Tel. +492343026 617, Fax +492343026 671 
higher than after purely occupational exposure. In these cases, indicative fibers for environmental exposure are tremolite fiber dust analytically demonstrated in lung tissue. The distribution of tumor types is similar after both occupational and environmental exposure. It has to be pointed out, however, that with increasing sample size and advancing tumor stage, the biphasic type clearly prevails. In the different studies, the sarcomatoid type is generally the most infrequent one. Sarcomatoid types show the most extensive metastatic spread and lead to the shortest survival periods. Here, the reported CT results seem to agree with pathological-anatomical findings. Regarding the involvement of lung parenchyma, the value of CT examinations needs to be analyzed critically; a marked lymphangial spread into the lung parenchyma and the contralateral pleura, influenced by the tumor stage, is characteristic for epithelioid and especially for biphasic subtypes. Obviously, here the demonstrative possibilities of imaging techniques have reached their limit. In terms of prognosis, however, these pathological-anatomical alterations are of extreme importance. Nevertheless, useful diagnostic criteria can be derived from the presented results, if the analyzed collectives include only mesothelioma patients. If and to what degree these criteria may possibly also be used in the differentiation of primary and secondary pleural tumors has to be investigated. The diagnostical value of pleural plaques is regarded by the authors with appropriate skepticism. Pleural plaques are frequent findings in mesothelioma and their occurrence in combination with pleural effusions is very suspicious of mesothelioma; however, it is not proven that pleural plaques are preneoplastic lesions.

\footnotetext{
References
1 Şenyiğit A, Bayram H, Babayiğit C, Topçu F, Nazaroğlu H, Bilici A, Leblebici İH: Malignant pleural mesothelioma caused by environmen- tal exposure to asbestos in the southeast of Tur- key. Respiration 2000;67:615-622.
2 Şenyiğit A, Babayiğit C, Gökirmak M, Topçu F, Asan E, Coşkunsel M, Işık R, Ertem M: Inci- dence of malignant pleural mesothelioma due to environmental asbestos fiber exposure in the southeast of Turkey. Respiration 2000;67:610- 614.

